\title{
Alterations of somatotropic function in prion disease in sheep
}

\author{
C Viguié, Y Chilliard ${ }^{1}$, V Gayrard, N Picard-Hagen, P Monget $^{2}$, \\ A Dutour ${ }^{3}$ and P-L Toutain
}

UMR 181, Experimental Pathophysiology and Toxicology, INRA National Veterinary School of Toulouse, 31076 Toulouse cedex 3, France
${ }^{1}$ Herbivore Research Unit, INRA, Theix, 63122 St-Genès-Champanelle, France
${ }^{2}$ UMR 85, INRA, 37380 Nouzilly, France
${ }^{3}$ UMR 501, Functional Interactions in Neuroendocrinology, INSERM-Université de la Méditerranée, Bd Pierre Dramard, 13015 Marseilles, France
(Requests for offprints should be addressed to C Viguié, UMR 181, INRA of Experimental Physiopathology and Toxicology, National Veterinary School of
Toulouse, 23 Chemin des Capelles, 31076 Toulouse cedex 3, France; Email c.viguie@envt.fr)

\begin{abstract}
This study aimed at investigating the possible linkage between natural scrapie and alterations of the somatotropic axis. Scrapie-affected ewes exhibited 2-fold higher mean $\mathrm{GH}$ concentrations during both autumn and spring. GH pulse frequencies were higher in scrapie-affected ewes than in control animals (mean \pm S.E.M. number of pulses/ $24 \mathrm{~h}: 10 \cdot 4 \pm 0 \cdot 9$ and $7 \cdot 6 \pm 0 \cdot 9$ for scrapie-affected and control ewes respectively) suggesting the involvement of central mechanisms. GH secretion induced by administration of an $\alpha_{2}$-adrenergic agonist, which acts centrally to stimulate GH secretion, was similar between healthy and scrapie-affected ewes (ratios of the area under the curve (AUC) of GH concentration after to the GH AUC before the agonist administration were $3 \cdot 6 \pm 1 \cdot 6$ and $4 \cdot 9 \pm 1 \cdot 0$ for
\end{abstract}

scrapie-affected and control ewes respectively). Finally, humoral markers and parameters of the metabolic status were determined to test the hypothesis that scrapieassociated alterations of $\mathrm{GH}$ secretion could be related to disruption of metabolic homeostasis. Glucose, insulin and urea plasma concentrations were higher in scrapie-affected than in healthy ewes. Neither leptin nor IGF-I levels were affected by scrapie. Total thyroxine (T4) was decreased in scrapie-affected ewes but free $\mathrm{T} 4$ and total and free tri-iodothyronine were not modified. In conclusion, our results showed the existence in scrapie-affected ewes of endocrine and metabolic alterations typical of acute illness proceeding, at least in part, from central mechanisms.

Journal of Endocrinology (2004) 183, 427-435

\section{Introduction}

Multiple endocrine alterations are common features of several neurodegenerative disorders including prionassociated diseases (Carp et al. 1989, Ye \& Carp 1996, Picard-Hagen et al. 1998, Busiguina et al. 2000, Ferrari et al. 2000, Gayrard et al. 2000). Despite the critical role of several endocrine systems in the maintenance of brain homeostasis and/or neuroprotective mechanisms, there has been little emphasis on the study of endocrine disorders in prion-related disease.

Prion diseases, and in particular scrapie, are chronic diseases often associated during their clinical stage with a wasting syndrome. One could expect such a disorder to arouse a full panel of adaptative mechanisms aimed at maintaining metabolic homeostasis. The somatotropic axis is a key endocrine system for metabolic homeostasis. It is therefore very likely that prion disease can be associated with modification of the somatotropic function.

Furthermore, several studies have suggested the existence of functional links between prion protein and the somatotropic axis at both the level of growth hormone (GH) and insulin-like growth factor-I (IGF-I) secretions and/or actions (Lasmezas et al. 1993, Castelnau et al. 1994, Satoh et al. 2000, Östlund et al. 2001a). This lays the foundation for putative alterations of the somatotropic function in disease associated with pathological modifications of the prion protein such as spongiform encephalopathy (Bounias \& Purdey 2002). Moreover, the somatotropic axis is deeply involved in neuroprotective mechanisms (Dore et al. 1997, Lackey et al. 2000). Thus, prion-related alteration of somatotropic function could play a critical role in the physiopathology of the disease through a lack of neuroprotective mechanisms.

Collectively, all the above considerations prompted us to investigate the somatotropic axis in sheep suffering from scrapie, a natural prion disease. We hypothesised that scrapie is associated with alterations of the somatotropic axis resulting from central mechanisms. To test this hypothesis, we investigated $\mathrm{GH}$ secretion as the hub component of the somatotropic axis lying at the interface between central and peripheral regulations. In relation to 
our general hypothesis, we investigated the implication of three major components of the regulation of somatotropic function, which all involve central mechanisms: (i) generation of GH pulsatility; (ii) $\alpha$-adrenergic control; and (iii) metabolic regulation of $\mathrm{GH}$ secretion. With regard to the $\alpha$-adrenergic control of GH secretion, we more particularly investigated responsiveness to an $\alpha_{2}$-adrenergic stimulus. Finally, we sought to determine whether clinical scrapie is associated with disruptions of metabolic homeostasis that could be related to perturbations of somatotropic function.

\section{Materials and Methods}

\section{General}

Experiments were performed in adult ovary-intact ewes and intact rams. These were allocated to healthy or scrapie-affected groups on the basis of unambiguous clinical signs (i.e. pruritis, tremor, ataxia, behavioural troubles). Working in field conditions with a natural disease rendered it almost impossible to date the beginning of the disease. However, all the scrapie-affected animals included in the study showed well-established clinical signs for several weeks which means that they were studied within the 6 months preceding their death. Animals were maintained under natural photoperiod and were fed hay ad libitum and concentrates and had free access to water. At least 1 week before the beginning of experiments involving serial sampling, the animals were placed in metabolic cages in such a way that they could see each other. Twenty-four hours before the beginning of each sampling session, an indwelling venous catheter was aseptically placed in one jugular vein of each animal. Blood was collected either on lithium heparinate (for GH assay) or EDTA (for leptin, glucose, non-esterified fatty acids (NEFA), insulin, urea and $\beta$-hydroxybutyrate assays) or in dry tubes (IGF-I assay). The natural light/dark cycle was disrupted during the $24 \mathrm{~h}$ bleeding sessions as the lights remained on throughout sampling.

All procedures involving animals were performed in accordance with the French legal requirements regarding the protection of laboratory animals and with the authorisation for animal experimentation no. 001889 of the French Ministry of Agriculture.

Objective 1: Characterisation of scrapie-associated alterations of somatotropic function: modification of mean GH concentration

Serial blood samples were collected as described above. $\mathrm{GH}$ secretion in sheep fluctuates with season (Barenton et al. 1987, 1988), so this experiment was performed during two different seasons. A first set of Manech Red Head (MRH) adult ewes $(n=7$ in both scrapie-affected and control groups) was sampled every hour for $24 \mathrm{~h}$ during the anoestrous season (June) and a second set $(n=7$ and 6 for the scrapie-affected and control groups respectively) was sampled every hour for $10 \mathrm{~h}$ (0900-1900 h) during the breeding season (November). Three scrapieaffected and four healthy Romanov rams were sampled every $15 \mathrm{~min}$ for $6 \mathrm{~h}$ during the non-breeding season (March) to check that increased GH secretion could be observed in scrapie-affected animals of both sexes.

All the experiments in this study were performed on naturally occurring scrapie in sheep collected directly from farms. Under such conditions, it was very difficult to obtain precise information about the age of animals. It was therefore not possible to balance groups for age in our experimental trials. As GH secretion fluctuates with age in sheep, as in other species (Falconer et al. 1979, Iranmanesh et al. 1991), an epidemiological survey was performed to assess the potential impact of age on the GH differences observed between healthy and scrapie-affected sheep. A single blood sample was collected at random from different populations of healthy and scrapie-affected ewes for $\mathrm{GH}$ assay. Data were obtained from 47 healthy ewes and 62 scrapie-affected ewes during the clinical stage of the disease. Scrapie diagnosis was confirmed post mortem in all the scrapie-affected ewes by histological examination of the brain.

\section{Objective 2: Are the effects of scrapie on mean GH concentration related to alteration of pulsatility?}

This experiment was performed in the middle of the anoestrous season (May) on seven healthy and seven scrapie-affected adult MRH ewes. The animals received a concentrate meal twice a day $(200 \mathrm{~g}$ between 0900 and $1000 \mathrm{~h}$ and $200 \mathrm{~g}$ between 1600 and $1700 \mathrm{~h}$ ) and had water and hay available ad libitum. Blood samples were collected every $10 \mathrm{~min}$ for $24 \mathrm{~h}$. One of every three samples was assayed for $\mathrm{GH}$. One control ewe became sick shortly after this sampling period and was not included in the subsequent sampling period to characterise metabolic status (objective 4).

\section{Objective 3: Are the effects of scrapie on mean GH concentration related to responsiveness to $\alpha_{2}$-adrenergic stimulation?}

Blood samples were obtained from four healthy and four scrapie-affected ewes for $3 \mathrm{~h}$ before and $3 \mathrm{~h}$ after an i.v. injection of an $\alpha_{2}$-adrenergic agonist (Romifidin Sedivet, Boehringer-Ingelheim, 51060 Reins, France; 0.05 mg/ $\mathrm{kg})$. Blood was collected every $15 \mathrm{~min}$ during the control period and 1, 2, 4, 8, 15 and thereafter every $15 \mathrm{~min}$ after Romifidin administration. As no changes in GH concentration were observed during the 8 min following the agonist injection, only samples collected at $15 \mathrm{~min}$ intervals were taken into account for the final analysis. 


\section{Objective 4: Is scrapie associated with metabolic disturbances?}

In a first experiment, animals of the GH pulsatility study (objective 2) were used to determine parameters and humoral markers of the metabolic status. One blood sample was collected just before (i.e. at least $12 \mathrm{~h}$ after distribution of the previous evening meal) and $4 \mathrm{~h}$ after distribution of the morning concentrate meal from the six remaining control and the seven scrapie-affected ewes. These samples were used for the measurement of metabolic parameters (urea, glycaemia, plasma $\beta$ hydroxybutyrate, non-esterified fatty acids (NEFA) and humoral markers of metabolic homeostasis (insulin, leptin and IGF-I). IGF-I and GH were conjointly assayed in the preprandial sample.

Thyroid hormones are critical for the maintenance of metabolic homeostasis and can markedly influence somatotropic function. In a second experiment, thyroid function was thus evaluated in two groups of animals (scrapie affected vs healthy). The animals used for this experiment were the anoestrous ewes of objective 1 . Blood samples were collected every hour for $24 \mathrm{~h}$. Total thyroxine (T4) and tri-iodothyronine (T3) concentrations were determined in one every third sample and free thyroid hormone concentrations in every sample.

\section{Assays}

GH was measured in duplicate aliquots of plasma $(100 \mu \mathrm{l})$ with an RIA using a double-antibody separation method with reagents provided by the National Hormone and Pituitary Program (NHPP, Harbor UCLA R.E.I., St Torrance, CA, USA) and according to their recommended procedure. The results are expressed in terms of NHPP ovine GH-1-5. Two series of assays were conducted in two different locations with two different batches of reagents. For the first series, two assays were performed, sensitivity averaged $0.4 \mathrm{ng} / \mathrm{ml}$ for $100 \mu \mathrm{l}$ aliquots and the mean intra- and interassay coefficients of variation (C.V.) were 6.2 and $10.8 \%$ respectively. For the second series, two assays were performed, sensitivity averaged $3.0 \mathrm{ng} / \mathrm{ml}$ for $100 \mu \mathrm{l}$ aliquots and mean intra- and interassay C.V. values were $10 \cdot 5$ and $15 \cdot 7 \%$ respectively.

Leptin was determined in duplicate on $100 \mu$ aliquots using a disequilibrium, double-antibody, ovine-specific RIA (Delavaud et al. 2000). Briefly, this assay utilised an anti-ovine leptin rabbit antibody at a final dilution of 1:30 000 and recombinant ovine $\left[{ }^{125} \mathrm{I}\right]$ leptin, with recombinant ovine leptin as standard. Sensitivity was $0.8 \mathrm{ng} / \mathrm{ml}$, and the intra- and interassay C.V. values were 6 and $9 \%$ respectively.

Total T3 and T4 were assayed in 50 and $20 \mu$ l single plasma aliquots respectively, using a veterinary RIA kit from Beckman Coulter Immunotech (Marseilles, France). Assay sensitivity was 2.5 and $0.5 \mathrm{ng} / \mathrm{ml}$ for $\mathrm{T} 4$ and $\mathrm{T} 3$ respectively. Free T3 and T4 were assayed in 100 and
$50 \mu \mathrm{l}$ single aliquots respectively, using Coat-A-Count RIA kits (Diagnostic Products Corp., Los Angeles, CA, USA), as previously validated for use in sheep (Moenter et al. 1991). The detection limit of the assay was $0 \cdot 1 \mathrm{ng} / \mathrm{ml}$ and $0.5 \mathrm{pg} / \mathrm{ml}$ for $\mathrm{T} 4$ and $\mathrm{T} 3$ respectively.

Insulin was determined using the commercial INSULIN-CT RIA kit (CIS Bio International, Gif-surYvette, France). The anti-insulin antiserum raised in guinea pig showed 100\% cross-reactivity with bovine insulin, and the reliability of the assay for ovine insulin determination was verified by a parallelism test performed on serial dilutions of a pool of plasma from adult ewes. Plasma samples were analysed in duplicate according to the manufacturer's instructions and the intra- and interassay C.V. values were 8.8 and $11.7 \%$ respectively.

Metabolites were determined by enzymatic assays with an ELAN auto-analyser (Merck-Clevenot, Nogent sur Marne, France) (Ferlay \& Chilliard 1999). Urea concentration was analysed with the Merck diagnostic kit (Chennevières-Lès-Louvres, France). NEFA concentration was measured with a Wako-Unipath NEFA-C kit (Oxoid, Dardilly, France). $\beta$-hydroxybutyrate concentrations and glucose concentrations were determined using the $\beta$-hydroxybutyrate dehydrogenase and glucosedehydrogenase methods respectively. The intra- and interassay C.V. values were 0.5 and $7 \cdot 0 \%$ for NEFA, $4 \cdot 1$ and $4 \cdot 0 \%$ for $\beta$-hydroxybutyrate, 5 and $4 \%$ for urea and 0.5 and $2.0 \%$ for glucose respectively.

Plasma samples $(25 \mu \mathrm{l})$ were incubated in acid medium $(0.01 \mathrm{M} \mathrm{HCl})$ for $30 \mathrm{~min}$ at room temperature to dissociate IGFs from IGF-binding proteins (IGFBPs), then ultrafiltered on Centricon 30 (Amicon, Epernon, France) to separate IGFs from IGFBPs. The ultrafiltrate containing IGFs was lyophilised, then taken up in a solution containing 0.03 $\mathrm{M} \mathrm{NaH}_{2} \mathrm{PO}_{4}, 500 \mu \mathrm{l} / 1$ Tween-20, $200 \mathrm{mg} / \mathrm{l}$ protamine sulfate, $200 \mathrm{mg} / 1 \mathrm{NaNO}_{3}$ and $3.72 \mathrm{~g} / 1$ EDTA $(\mathrm{pH} 7 \cdot 4)$ and incubated for 2 days in a final volume of $500 \mu \mathrm{l}$ with a specific polyclonal anti-human IGF-I antibody (1:120 000 dilution) that cross-reacted with ovine IGF-I (gift from J Closset, Centre Hospitalo-Universitaire de Liege, Belgium) and ${ }^{125}$ I-human IGF-I (10 000 c.p.m./ tube). Iodination was performed using the iodogene method. Samples were tested at two concentrations plus one blank (without antibody), each in triplicate so as to confirm parallelism with the standard curve. After incubation, the free and bound IGFs were separated using albumin-coated charcoal. The threshold sensitivity of the assay was $1-2 \mathrm{ng} / \mathrm{ml}$ plasma. Intra- and interassay C.V. values were close to 5 and $10 \%$ respectively.

\section{Data analysis}

Pulses were identified using an adaptation of the method described by Wallace \& MacNeilly (1986). Briefly, a pulse was identified as soon as the GH concentration reached a higher value than the mean value of the two preceding 
points by at least two standard deviations. The pulse that lasted as long as the $\mathrm{GH}$ concentration at a given time remained higher than the mean value of the two following points by at least two standard deviations. The standard deviation under consideration was estimated for each point from the mean intra-assay C.V. according to the following equation: S.D. $=$ C.V. $\times$ mean concentration $/ 100$.

When variances between groups were nonhomogenous, the data were log transformed before statistical analysis. GH concentration profiles over time were compared between healthy and scrapie-affected ewes using repeated measures ANOVA including ewes as a random effect factor, and time, group and their interactions as fixed effect factors. The effect of the adrenergic agonist on GH concentrations was analysed using a linear model including ewes as a random effect factor, and period relative to the agonist administration, time within period and their interactions as fixed effect factors. The area under the curve (AUC) ratios, mean GH concentrations, pulse amplitude, mean $\mathrm{GH}$ concentration during interpulses, GH mean concentration and age were compared between healthy and scrapie-affected ewes using an unpaired $t$-test. Pulse frequencies were analysed with a nonparametric Mann-Whitney test. Metabolic parameters were analysed using a repeated measures ANOVA, including ewes as a random effect factor, and meal, group and their interactions as fixed effect factors. In objective 4, the relative effects of disease and GH on IGF-I concentration were analysed using a linear model including the disease as a fixed effect factor and GH concentration as a covariate.

\section{Results}

Objective 1: Characterisation of scrapie-associated alterations of somatotropic function: modification of mean GH concentration

The GH secretory profiles in hourly samples differed between scrapie-affected and healthy ewes (interaction daytime $\times$ group $P<0 \cdot 05)$. This difference was observed both in animals sampled during the breeding season and in animals sampled during the anoestrous season. This resulted in higher mean $\mathrm{GH}$ concentrations in scrapieaffected ewes (Fig. 1). Similarly, the GH concentrations in males were more than 2-fold higher in scrapie-affected animals (means \pm S.E.M.: $4.8 \pm 1.5 \mathrm{ng} / \mathrm{ml}$ vs $1.9 \pm 0.4 \mathrm{ng}$ / $\mathrm{ml}$ for healthy rams; $P<0 \cdot 05$ ).

In our epidemiological survey, the mean GH concentration in scrapie-affected sheep was higher than in healthy controls (means \pm S.E.M.: $4 \cdot 0 \pm 0.7$ and $1.4 \pm 0.3 \mathrm{ng} / \mathrm{ml}$ for scrapie-affected and healthy ewes respectively; $P<0 \cdot 001$ ). In contrast, mean ages did not differ significantly between the two populations $(3 \cdot 2 \pm 0 \cdot 3$ and $2 \cdot 5 \pm 0 \cdot 3$ years for healthy and scrapie-affected ewes respectively). GH concentrations measured in a single sample showed high inter-individual variability which was probably due to the
Anoestrous season

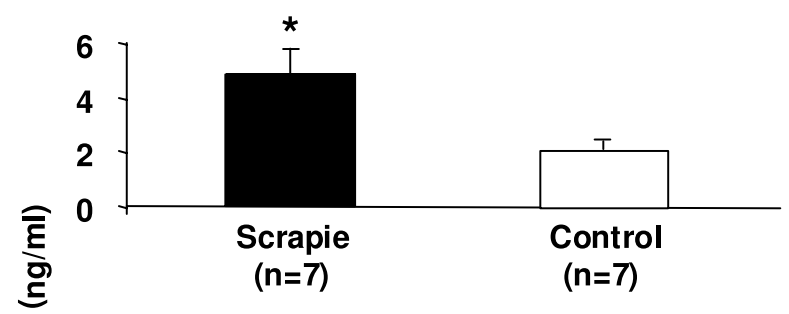

Breeding season

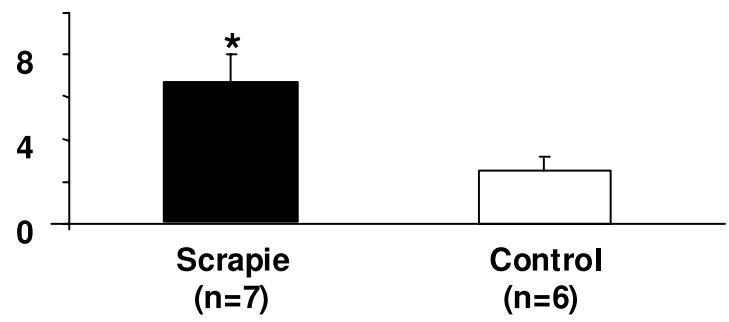

Figure 1 Mean \pm S.E.M. GH concentrations in scrapie-affected (solid bars) and healthy (open bars) ovary-intact ewes during the breeding (top panel) or anoestrous (bottom panel) seasons. GH was measured in samples collected every hour for $10 \mathrm{~h}$ from one set of animals during the breeding season and for $24 \mathrm{~h}$ from another set of animals during the anoestrous season. ${ }^{*} P<0 \cdot 05$.

pulsatile secretion of this hormone. It is noteworthy, however, that despite this variability, the large number of animals included in the survey enabled us to show a statistically significant difference in GH concentration between healthy and scrapie-affected ewes.

Objective 2: Are the effects of scrapie on mean GH concentration related to alteration of pulsatility?

The mean GH concentration over $24 \mathrm{~h}$ and the mean concentrations of interpulse episodes tended to be higher in scrapie-affected ewes $(P=0.07$ and 0.08 respectively). Figure 2 depicts representative examples of GH secretory profiles from one healthy control and one scrapie-affected ewe and $\mathrm{GH}$ mean \pm S.E.M. concentrations in both groups. The GH pulse frequency was significantly higher in scrapie-affected ewes $(P=0 \cdot 04)$, but neither pulse amplitude nor mean pulse area differed between the groups (Fig. 3; $P=0.5$ and 0.4 for amplitude and area respectively).

Objective 3: Are the effects of scrapie on mean GH concentration related to responsiveness to $a_{2}$-adrenergic stimulation?

Mean GH concentrations during the control period were significantly higher in scrapie-affected ewes $(P<0 \cdot 05)$. As a result, the AUC of $\mathrm{GH}$ concentration vs time during the control period was $3 \cdot 3$-fold higher in scrapie-affected than in healthy ewes (means \pm S.E.M.: $33.5 \pm 10.5$ and 


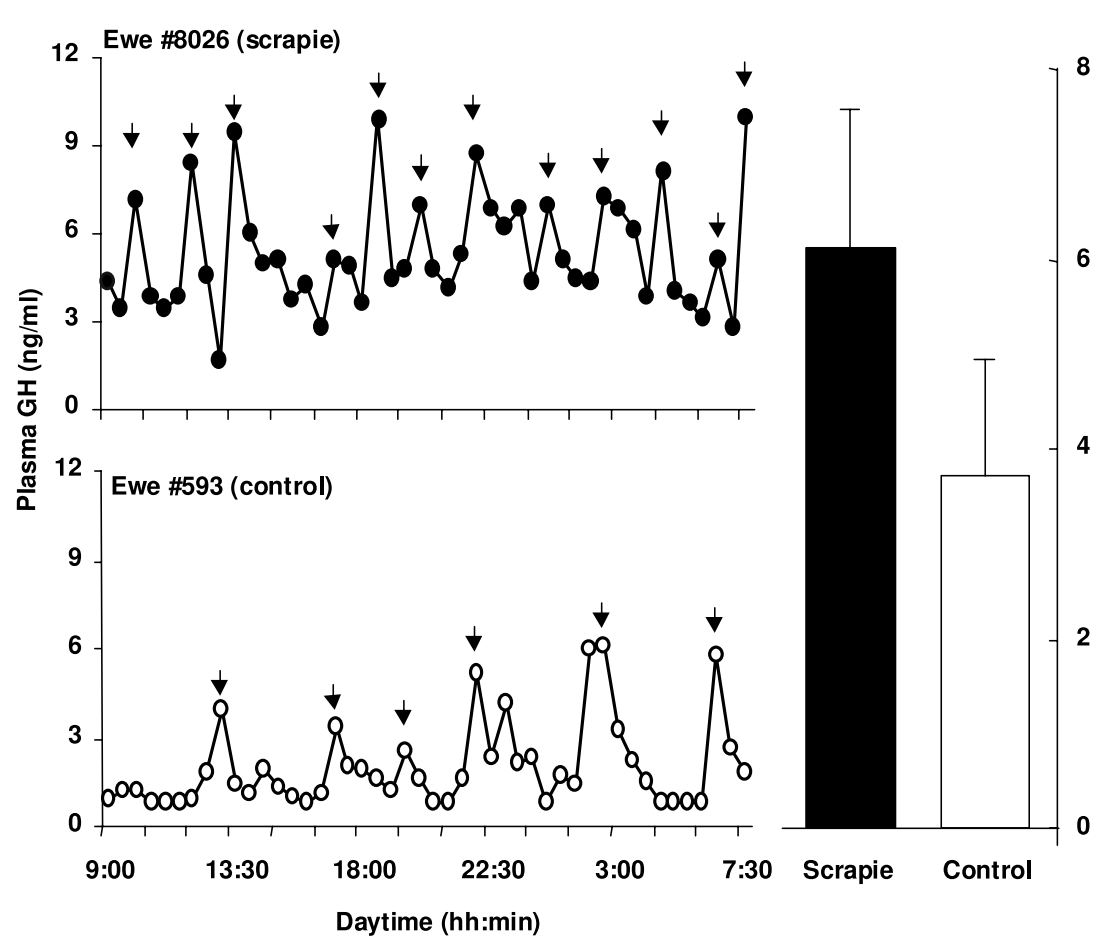

Figure 2 Representative examples of GH secretory profiles in one scrapie-affected (top panel) and one control healthy (bottom panel) ewe. GH was measured in blood samples collected every 30 min for $24 \mathrm{~h}$ during the anoestrous season in ovary-intact ewes. Arrows indicate identified pulses. The bar graph depicts the mean \pm S.E.M. GH concentrations in both groups. $P=0 \cdot 07$.

$10 \cdot 1 \pm 2 \cdot 6 \mathrm{ng} . \mathrm{h} / \mathrm{ml}$ for scrapie-affected and control ewes respectively). Romifidin administration induced a dramatic increase in GH concentrations within $15 \mathrm{~min}$ in both groups. The GH AUC following the administration of $0.05 \mathrm{mg} / \mathrm{kg}$ Romifidin was $2 \cdot 4$-fold higher in scrapieaffected than in healthy ewes (means \pm S.E.M.: $98 \cdot 1 \pm 37 \cdot 2$ and $41 \cdot 2 \pm 9 \cdot 7 \mathrm{ng} . \mathrm{h} / \mathrm{ml}$ for scrapie-affected and control ewes respectively). However, the ratio of the AUC post-injection to the AUC pre-injection did not differ between groups (Fig. 4).

\section{Objective 4: Is scrapie associated with metabolic disturbances?}

At the time of this experiment, body weights were not different between healthy and scrapie-affected ewes (mean \pm S.E.M.: body weight $40 \pm 2$ and $37 \pm 2 \mathrm{~kg}$ for healthy and scrapie-affected ewes respectively; $P=0 \cdot 3$ ) suggesting that body conditions were similar between groups. In agreement with this observation, no difference in mean leptin concentration could be seen. The recording of the concentrate intake (the main source of energy) did not show any difference between the two groups. Concentrate intake had no significant effect on the hormonal or metabolic parameters measured except for NEFA (Table 1). Indeed, a significant interaction between group and period (before or after the meal) was observed, characterised by a decrease in circulating concentrations of NEFA $4 \mathrm{~h}$ after the concentrate meal in scrapie-affected ewes only. Independently of food intake, scrapie-affected ewes showed higher plasma glucose concentrations (Table 1) associated with higher insulin $(P<0 \cdot 05)$ and urea $(P<0 \cdot 05)$ concentrations. IGF-I concentration did not differ significantly between groups $(P>0 \cdot 05)$. No significant interactions between group and $\mathrm{GH}$ concentration measured in the preprandial sample on IGF-I concentration could be observed $(P=0 \cdot 8)$.

In the second experiment, thyroid status was assessed in two other groups of animals (healthy and scrapie affected). Mean total T4 concentration was significantly lower in scrapie-affected ewes (means \pm S.E.M.: $75 \cdot 8 \pm 5 \cdot 1$ and $58 \cdot 0 \pm 2.7 \mathrm{ng} / \mathrm{ml}$ in healthy and scrapie-affected ewes respectively). In contrast, neither total T3, nor free T3 and T4 concentrations differed significantly between groups (means \pm S.E.M. for total T3: $1 \cdot 5 \pm 0 \cdot 1$ and $1 \cdot 3 \pm 0.09 \mathrm{ng} /$ $\mathrm{ml}$; free $\mathrm{T} 4: 0.95 \pm 0.06$ and $0.75 \pm 0.08 \mathrm{ng} / \mathrm{ml}$; free T3: $1.73 \pm 0.09$ and $1.42 \pm 0 \cdot 22 \mathrm{pg} / \mathrm{ml}$ for healthy and scrapie-affected groups respectively).

\section{Discussion}

Our study has clearly demonstrated that scrapie is associated with alterations in $\mathrm{GH}$ secretion. These alterations are 

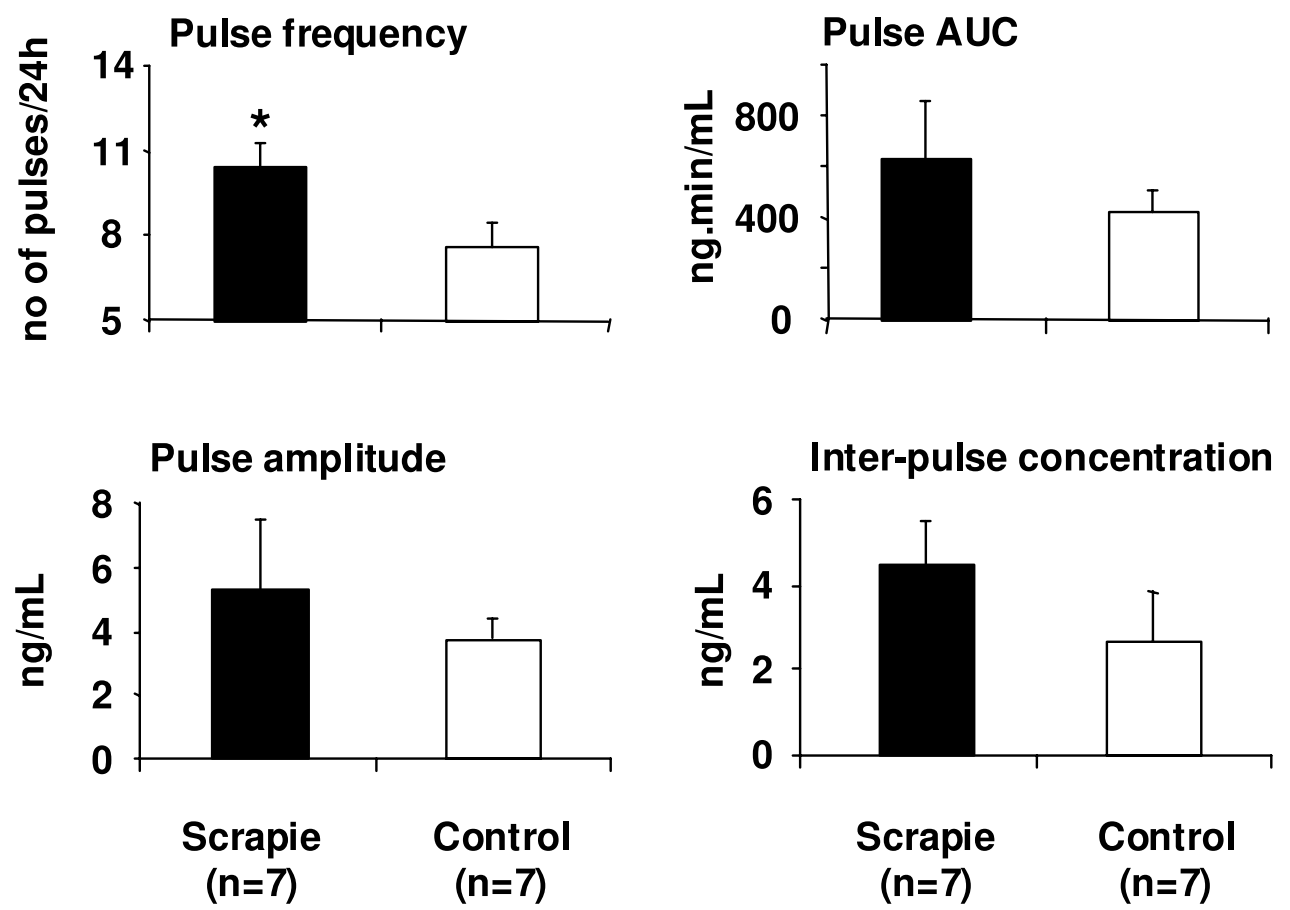

Figure 3 Mean \pm S.E.M. number of GH pulses/24 h, AUC and amplitude of GH pulses and GH concentrations during interpulse episodes in scrapie-affected (solid bars) and healthy control (open bars) ovary-intact ewes. $P=0.04,0.4,0.5$ and 0.08 for pulse number, pulse AUC, amplitude and interpulse GH concentration respectively.

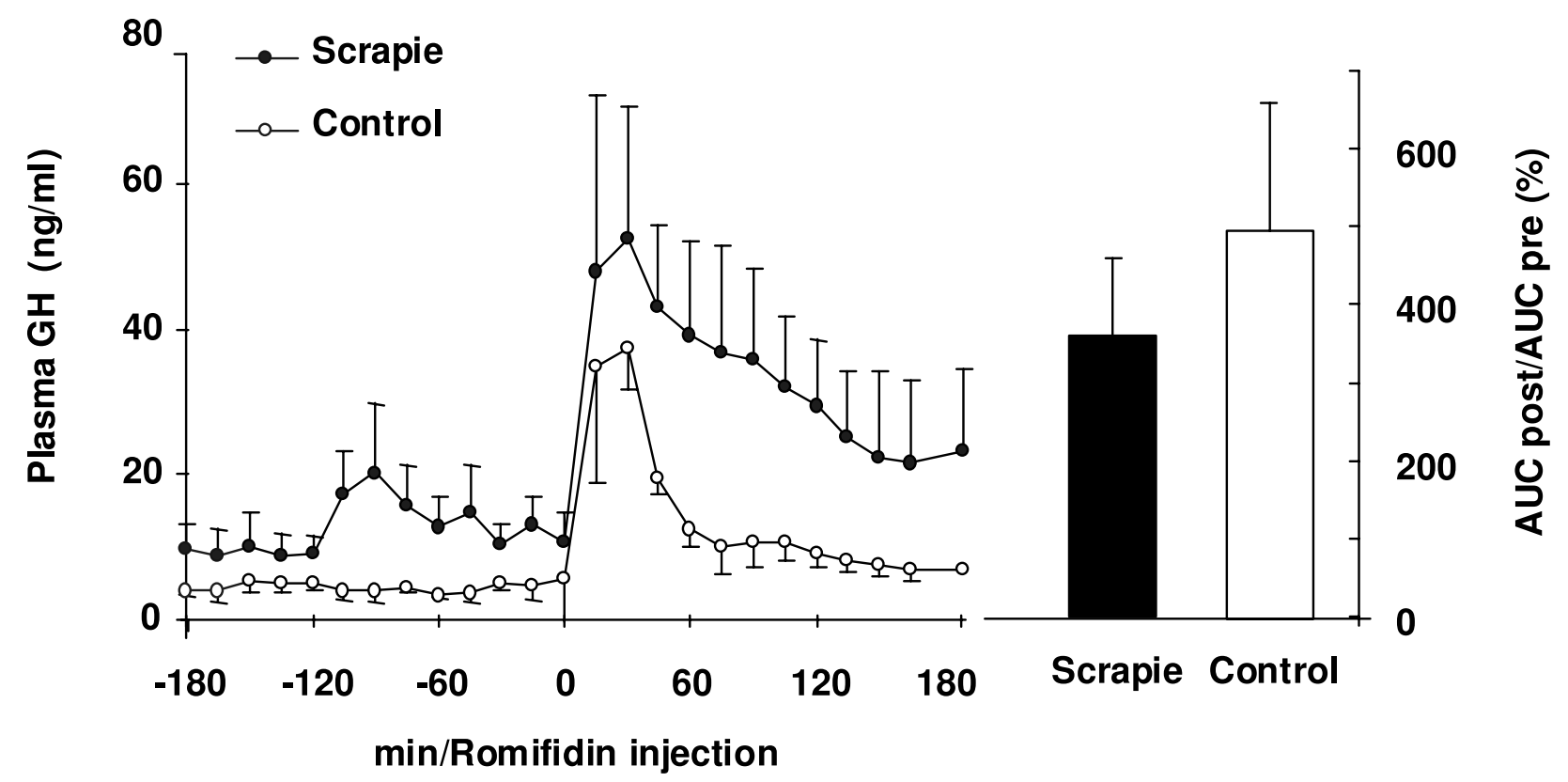

Figure 4 The left panel indicates the mean \pm S.E.M. GH concentrations in blood samples collected every 15 min for $3 \mathrm{~h}$ before and $3 \mathrm{~h}$ after an i.v. injection of an $\alpha_{2}$-adrenergic agonist (Romifidin, $0.05 \mathrm{mg} / \mathrm{kg}$ at $0 \mathrm{~min}$ ) in scrapie-affected $(n=4)$ and healthy control $(n=4)$ ovary-intact ewes. The left panel describes the mean \pm S.E.M. ratio of AUC of GH vs time after to the GH AUC before agonist administration in both groups. 
Table 1 Effect of scrapie and meal on the metabolic status of adult ovary-intact ewes. Values are expressed as means \pm S.E.M. These parameters were measured in blood samples collected $4 \mathrm{~h}$ before (preprandial) and $4 \mathrm{~h}$ after (postprandial) a concentrate meal

\begin{tabular}{|c|c|c|c|c|}
\hline & \multicolumn{2}{|l|}{ Scrapie } & \multicolumn{2}{|l|}{ Control } \\
\hline & Preprandial & Postprandial & Preprandial & Postprandial \\
\hline IGF-I (ng/ml) & $133 \pm 23$ & & $102 \pm 21$ & \\
\hline $\mathrm{GH}(\mathrm{ng} / \mathrm{ml})$ & $11 \cdot 6 \pm 2 \cdot 8$ & & $8 \cdot 0 \pm 3 \cdot 3$ & \\
\hline Leptin $(\mathrm{ng} / \mathrm{ml})$ & $3 \cdot 7 \pm 0 \cdot 1$ & $3 \cdot 6 \pm 0 \cdot 1$ & $4 \cdot 4 \pm 0 \cdot 5$ & $4 \cdot 4 \pm 0 \cdot 4$ \\
\hline Insulin $(\mu \bigcup \mathrm{I} / \mathrm{ml})^{*}$ & $24 \pm 5$ & $28 \pm 7$ & $11 \pm 1$ & $15 \pm 3$ \\
\hline Glucose $(\mathrm{g} / \mathrm{l})^{*}$ & $0.74 \pm 0.04$ & $0.74 \pm 0.03$ & $0.58 \pm 0.03$ & $0.57 \pm 0.03$ \\
\hline NEFA $(\mathrm{mmol} / \mathrm{l}) \dagger$ & $0 \cdot 36 \pm 0 \cdot 07$ & $0 \cdot 13 \pm 0 \cdot 03$ & $0 \cdot 29 \pm 0 \cdot 08$ & $0 \cdot 30 \pm 0 \cdot 11$ \\
\hline 3-OH-butyrate $(\mathrm{mmol} / \mathrm{l})$ & $0 \cdot 34 \pm 0 \cdot 04$ & $0 \cdot 41 \pm 0 \cdot 03$ & $0 \cdot 42 \pm 0 \cdot 10$ & $0 \cdot 43 \pm 0.07$ \\
\hline Urea $(\mathrm{g} / \mathrm{l})^{*}$ & $0 \cdot 32 \pm 0 \cdot 02$ & $0 \cdot 33 \pm 0 \cdot 02$ & $0 \cdot 23 \pm 0 \cdot 05$ & $0 \cdot 24 \pm 0 \cdot 04$ \\
\hline
\end{tabular}

characterised by an increase in GH plasma concentrations observed during both the breeding and the anoestrous seasons and in both sexes. According to our epidemiological survey, age is unlikely to be a determining factor for the difference in $\mathrm{GH}$ concentration observed between healthy and scrapie-affected sheep. Higher GH concentration results, at least in part, from increased pulse frequency suggesting that central mechanisms are involved. However, it is unlikely that an increased responsiveness to $\alpha_{2}$-adrenergic central stimulatory pathways is involved. Finally, multiple metabolic disorders (increased glycaemia, insulinaemia, uraemia and higher responsiveness of NEFA to concentrate meal intake) were observed in scrapieaffected animals.

Although scrapie can be considered as a long-lasting chronic disease, our clinical data do not fit the classical pathophysiological endocrine scheme of such conditions. Indeed, chronic diseases such as arthritis (Templ et al. 1996, Lopez-Calderon et al. 1999), parasitism (Elsasser et al. 1988) and the chronic phase of critical illness (Ligtenberg et al. 2001, Van Den Berghe 2002) are all associated with a decrease in one or more pituitary functions, including somatotropic functions, which results in a catabolic and wasting syndrome state.

In contrast, a stimulation of $\mathrm{GH}$ secretion is often observed during the initial phase of acute illness and in experimental models of acute diseases such as endotoxin challenge in sheep (Briard et al. 1998) and humans (Lang et al. 1997). Increased exposure to GH, in acute pathologies associated with severe catabolism and malnutrition, is believed to allow full expression of beneficial effects related to the initial endocrine stress response. For example, the stimulation of GH secretion in acute illness results in direct lipolytic, insulin-antagonising and immune stimulatory actions (Van Den Berghe 2002). Although scrapie is a long-lasting chronic wasting disease, most of our observations seem to fit the pathophysiological endocrine scheme of acute illness. In particular, our results clearly suggest that a relative state of insulinoresistance, characterised by increased glycaemia despite an increase in insulinaemia, might occur in scrapie-affected sheep. Increased GH concentration in scrapie-affected ewes is likely to mediate a state of insulinoresistance (Clemmons 2004). Alternatively, this state may be related to prion-induced alterations of insulin receptor gene expression and functionality as shown in prion-infected neuroblastoma cells (Östlund et al. 2001b).

Non-metabolic beneficial effects might arise from increased GH secretion. Indeed, GH exhibits IGF-Iindependent neuroprotective effects (Scheepens et al. 2001) and can induce the expression of suppressors of cytokine signalling (Adams et al. 1998, Davey et al. 1999, Wu et al. 2003) particularly during the acute phase of different injuries. Scrapie, like other natural or experimental spongiform encephalopathies, is associated with an increased expression of cytokines in the central nervous system, in particular tumour necrosis factor- $\alpha$ and interleukin-1 (Williams et al. 1994, 1997, Kim et al. 1999, Baker et al. 2002, Eikelenbroom et al. 2002). Increased GH concentration might therefore help to contain the devastating effects of prolonged exposure of the brain to cytokines and be part of the panel of mechanisms aimed at limiting the neurodegenerative process.

Putative mechanisms underlying the stimulation of $\mathrm{GH}$ secretion remain to be determined. In particular, the question arises as to whether central mechanisms are involved. Pulsatility of GH secretion typically results from central mechanisms, namely hypothalamic inhibitory somatostatinergic and stimulatory GH-releasing hormone (GHRH) tones (Robinson 1991). Our results show that $\mathrm{GH}$ pulsatile secretion is modified in scrapie-affected ewes, which therefore suggests that central mechanisms are involved in the stimulation of $\mathrm{GH}$ secretion observed in such animals. GHRH and somatostatin secretions are themselves under the control of several neuromediators. For example, the stimulation of GH secretion by $\alpha_{2^{-}}$ adrenergic agonists in sheep results from an increase in GHRH secretion in the portal blood (Magnan et al. 1994). 
Interestingly, our observation that $\mathrm{GH}$ response to an $\alpha_{2}$-adrenergic agonist is not modified by scrapie suggests that the responsiveness of the central component of the somatotropic axis to $\alpha_{2}$-adrenergic stimulatory pathways is not profoundly modified by scrapie. Cytokines can also alter somatotropic functions at a central level. It is therefore tempting to hypothesise that scrapie-related cytokine up-regulation in the diseased brains may mediate the stimulation of somatotropic function.

Alterations in $\mathrm{GH}$ secretion could result from intimate dysfunctioning of the main regulatory mechanisms of the hypothalamo-hypophysial somatotropic axis and, in particular, at the level of the interactions between $\mathrm{GH}$ and IGF-I. For example, in many pathological situations associated with severe catabolism, the regulation of IGF-I and GH secretions appears to be uncoupled through a mechanism of acquired resistance to GH. IGF-I secretion thus escapes GH stimulatory control, and this results in a decrease in IGF-I concentration leading to a low level of negative feedback of IGF-I on GH secretion (Van Den Berghe 2002). Our results failed to demonstrate a reduction in total IGF-I concentration typical of GH-acquired resistance in scrapie-affected ewes. However, the fact that IGF-I was not increased in those ewes having shown increased GH pulse frequency suggests that a certain degree of dissociation between GH and IGF-I secretion might occur in scrapie-affected ewes. Thus, in the absence of direct assessment of IGF-I responsiveness to the stimulatory action of $\mathrm{GH}$, the hypothesis of a scrapie-associated state of acquired GH resistance cannot be completely ruled out. Another possible and clinically relevant endocrine interaction that might explain our results would be a decrease in the efficacy of the IGF-I negative feedback. Such a reduction in the negative feedback of IGF-I on GH secretion could reflect a general lack of action of IGF-I. This mechanistic hypothesis is supported by in vitro data obtained from scrapie-infected neuroblastoma cells which showed an over-expression of a truncated functionally impaired IGF-I receptor (Satoh et al. 2000). Further investigations are required to demonstrate a lack of action of IGF-I in vivo in transmissible spongiform encephalopathies.

Metabolic homeostasis is intimately linked to the somatotropic function as well as other endocrine systems. Thyroid hormones and leptin are two endocrine systems critical for metabolic homeostasis that can interact with somatotropic function. The present study failed to show alterations of leptin concentration in scrapie-affected ewes. Modifications of the thyroid axis were limited to a decrease in total T4 but no modification of total T3 and free T3 and T4 concentrations. Thus, it was difficult to relate $\mathrm{GH}$ modification to alterations in thyroid functions. It is interesting to note, however, that this decrease in total $\mathrm{T} 4$ concentration could be related to a decrease in thyrotrophin secretion.

Our results have shown the existence of endocrine alterations typical of acute illness in scrapie-affected sheep.
It is tempting to hypothesise that the maintenance of those endocrine alterations in this chronic disease is related to a high level of expression of cytokines in the diseased brain. Such a hypothesis assumes that the central components of the somatotropic axis, namely GHRH and somatostatin secretions, are altered in scrapie. The modifications in GH pulse frequency observed in this study are consistent with such a hypothesis.

\section{Acknowledgements}

The authors would like to thank the experimental INRA unit UE 65 and its director $F$ Eychenne for providing scrapie-infected animals and enabling us to perform an epidemiological survey on his scrapie-infected Romanov flock. GH assay reagents were kindly provided by Dr A Parlow of the National Hormone and Pituitary Program. The assistance of Carole Delavaud and Martine Tourret (Herbivore Research Unit) in the determination of plasma leptin, insulin and metabolites was highly appreciated.

\section{Funding}

This study was supported by grants from the French National Institute for Agricultural Research (INRA), from Groupe d'Intérêt Scientifique prion and from the General Direction for Education and Research (DGER) of the French Ministry of Agriculture. The authors declare that there is no conflict of interest relative to the major sources of funding that would prejudice their impartiality relative to the results of the study.

\section{References}

Adams TE, Hansen JA, Starr R, Nicola NA, Hilton DJ \& Billestrup N 1998 Growth hormone preferentially induces the rapid, transient expression of SOCS-3, a novel inhibitor of cytokine receptor signaling. Journal of Biological Chemistry 273 1285-1287.

Baker CA, Martin D \& Manuelidis L 2002 Microglia from Creutzfeldt-Jakob disease-infected brains are infectious and show specific mRNA activation profiles. Journal of Virology 76 10905-10913.

Barenton B, Chabanet C \& Pelletier J 1987 Influence of photoperiod and protein diet on growth hormone secretion in rams. Proceedings of the Society of Experimental Biology and Medicine 185 312-317.

Barenton B, Ravault JP, Chabanet C, Daveau A, Pelletier J \& Ortavant R 1988 Photoperiodic control of growth hormone secretion and body weight in rams. Domestic Animal Endocrinology $\mathbf{5}$ 247-255.

Bounias M \& Purdey M 2002 Transmissible spongiform encephalopathies: a family of etiologically complex diseases - a review. Science of the Total Environment 297 1-19.

Briard N, Guillaume V, Frachebois C, Rico-Gomez M, Sauze N, Oliver C \& Dutour A 1998 Endotoxin injection increases growth hormone and somatostatin secretion in sheep. Endocrinology 139 2662-2669. 
Busiguina S, Fernandez AM, Barrios V, Clark R, Tolbert DL, Berciano J \& Torres-Aleman I 2000 Neurodegeneration is associated to changes in serum insulin-like growth factors. Neurobiology Disorders 7 657-665.

Carp RI, Kim YS \& Callahan SM 1989 Scrapie-induced alterations in glucose tolerance in mice. Journal of General Virology 70 827-835.

Castelnau P, Lazarini F, Deslys JP \& Dormont D 1994 Prion protein gene expression in cultured astrocytes treated by recombinant growth hormone and insulin-like growth factor. Experimental Neurology 130 407-410.

Clemmons DR 2004 The relative roles of growth hormone and IGF-1 in controlling insulin sensitivity. Journal of Clinical Investigation 113 $25-27$.

Davey HW, McLachlan MJ, Wilkins RJ, Hilton DJ \& Adams TE 1999 STAT5b mediates the GH-induced expression of SOCS-2 and SOCS-3 mRNA in the liver. Molecular and Cellular Endocrinology 158 111-116.

Delavaud C, Bocquier F, Chilliard Y, Keisler DH, Gertler A \& Kann G 2000 Plasma leptin determination in ruminants: effect of nutritional status and body fatness on plasma leptin concentration assessed by a specific RIA in sheep. Journal of Endocrinology 165 519-526.

Dore S, Kar S \& Quirion R 1997 Rediscovering an old friend, IGF-I potential use in the treatment of neurodegenerative diseases. Trends in Neuroscience 20 326-331.

Eikelenboom P, Bate C, Van Gool WA, Hoozemans JJ, Rozemuller JM, Veerhuis R \& Williams A 2002 Neuroinflammation in Alzheimer's disease and prion disease. Glia 40 232-239.

Elsasser TH, Rumsey TS, Hammond AC \& Fayer R 1988 Influence of parasitism on plasma concentrations of growth hormone, somatomedin-C and somatomedin-binding proteins in calves. Journal of Endocrinology 116 191-200.

Falconer J, Forbes JM, Jones R \& Rose D 1979 Changes in somatomedin-like activity and concentrations of growth hormone and prolactin in the plasma of castrated growing lambs. Journal of Developmental Physiology $1337-342$.

Ferlay A \& Chilliard Y 1999 Effects of the infusion of non-selective beta-, and selective beta1- or beta2-adrenergic agonists, on body fat mobilisation in underfed or overfed non-pregnant heifers. Reproduction, Nutrition, Development 39 409-421.

Ferrari E, Fioravanti M, Magri F \& Solerte SB 2000 Variability of interactions between neuroendocrine and immunological functions in physiological aging and dementia of the Alzheimer's type. Annals of the New York Academy of Sciences 917 582-596.

Gayrard V, Picard-Hagen N, Grino M, Sauze N, Grandjean C, Galea J, Andreoletti O, Schelcher F \& Toutain PL 2000 Major hypercorticism is an endocrine feature of ewes with naturally occurring scrapie. Endocrinology 141 988-994.

Iranmanesh A, Lizarralde G \& Veldhuis JD 1991 Age and relative adiposity are specific negative determinants of the frequency and amplitude of growth hormone $(\mathrm{GH})$ secretory bursts and the half-life of endogenous GH in healthy men. Journal of Clinical Endocrinology and Metabolism 73 1081-1088.

Kim JI, Ju WK, Choi JH, Choi E, Carp RI, Wisniewski HM \& Kim YS 1999 Expression of cytokine genes and increased nuclear factor-kappa B activity in the brains of scrapie-infected mice. Brain Research. Molecular Brain Research 73 17-27.

Lackey BR, Gray SL \& Henricks DM 2000 Does the insulin-like growth factor system interact with prostaglandins and proinflammatory cytokines during neurodegeneration? Proceedings of the Society for Experimental Biology and Medicine 224 20-27.

Lang CH, Pollard V, Fan J, Traber LD, Traber DL, Frost RA, Gelato MC \& Prough DS 1997 Acute alterations in growth hormone-insulin-like growth factor axis in humans injected with endotoxin. American Journal of Physiology 273 R371-R378.

Lasmezas C, Deslys JP \& Dormont D 1993 Recombinant human growth hormone and insulin-like growth factor I induce PrP gene expression in PC12 cells. Biochemical and Biophysical Research Communications 196 1163-1169.
Ligtenberg JJ, Girbes AR, Beentjes JA, Tulleken JE, van der Werf TS \& Zijlstra JG 2001 Hormones in the critically ill patient: to intervene or not to intervene? Intensive Care Medicine $\mathbf{2 7}$ $1567-1577$.

Lopez-Calderon A, Soto L \& Martin AI 1999 Chronic inflammation inhibits $\mathrm{GH}$ secretion and alters the serum insulin-like growth factor system in rats. Life Science 65 2049-2060.

Magnan E, Cataldi M, Guillaume V, Mazzocchi L, Dutour A, Razafindraibe H, Sauze N, Renard M \& Oliver C 1994 Role of growth hormone $(\mathrm{GH})$-releasing hormone and somatostatin in the mediation of clonidine-induced GH release in sheep. Endocrinology 134 562-567.

Moenter SM, Woodfill CJ \& Karsch FJ 1991 Role of the thyroid gland in seasonal reproduction: thyroidectomy blocks seasonal suppression of reproductive neuroendocrine activity in ewes. Endocrinology 128 1337-1344.

Östlund P, Lindegren H, Pettersson C \& Bedecs K 2001a Up-regulation of functionally impaired insulin-like growth factor-1 receptor in scrapie-infected neuroblastoma cells. Journal of Biological Chemistry 276 36110-36115.

Östlund P, Lindegren H, Pettersson C \& Bedecs K $2001 b$ Altered insulin receptor processing and function in scrapie-infected neuroblastoma cell lines. Molecular Brain Research 97 161-170.

Picard-Hagen N, Gayrard V, Andreoletti O, Galea J, Grandjean C, Mandon-Maurice F, Cabanie P, Schelcher F \& Toutain PL 1998 Melatonin and prolactin secretion profile in naturally occurring scrapie in ewe. Journal of Pineal Research 24 117-122.

Robinson IC 1991 The growth hormone secretory pattern: a response to neuroendocrine signals. Acta Paediatrica Scandinavica 372 $70-80$.

Satoh J, Kuroda Y \& Katamine S 2000 Gene expression profile in prion protein-deficient fibroblasts in culture. American Journal of Pathology 157 59-68.

Scheepens A, Sirimanne ES, Breier BH, Clark RG, Gluckman PD \& Williams CE 2001 Growth hormone as a neuronal rescue factor during recovery from CNS injury. Neuroscience 104 677-687.

Templ E, Koeller M, Riedl M, Wagner O, Graninger W \& Luger A 1996 Anterior pituitary function in patients with newly diagnosed rheumatoid arthritis. British Journal of Rheumatology 3 350-356.

Van den Berghe G 2002 Dynamic neuroendocrine responses to critical illness. Frontiers in Neuroendocrinology 23 370-391.

Wallace JM \& McNeilly AS 1986 Changes in FSH and the pulsatile secretion of LH during treatment of ewes with bovine follicular fluid throughout the luteal phase of the oestrous cycle. Journal of Endocrinology 111 317-327.

Williams AE, van Dam AM, Man-A-Hing WK, Berkenbosch F, Eikelenboom P \& Fraser H 1994 Cytokines, prostaglandins and lipocortin-1 are present in the brains of scrapie-infected mice. Brain Research 654 200-206.

Williams A, Van Dam AM, Ritchie D, Eikelenboom P \& Fraser H 1997 Immunocytochemical appearance of cytokines, prostaglandin E2 and lipocortin-1 in the CNS during the incubation period of murine scrapie correlates with progressive $\mathrm{PrP}$ accumulations. Brain Research 754 171-180.

Wu X, Herndon DN \& Wolf SE 2003 Growth hormone down-regulation of interleukin-1 beta and interleukin-6 induced acute phase protein gene expression is associated with increased gene expression of suppressor of cytokine signal-3. Shock 19 314-320.

Ye X \& Carp RI 1996 Histopathological changes in the pituitary glands of female hamsters infected with the $139 \mathrm{H}$ strain of scrapie. Journal of Comparative Pathology 114 291-304.

Received in final form 28 July 2004 Accepted 2 August 2004 